\title{
$\mathrm{RANS}$ 및 $\mathrm{LES}$ 를 이용한 리세스가 있는 동축분사기의 유동혼합에 대한 수치해석
}

박태선* $*^{+}$

\section{RANS-LES Simulations of Scalar Mixing in Recessed Coaxial Injectors}

\author{
Tae Seon Park* ${ }^{+}$
}

\begin{abstract}
The turbulent flow characteristics in a coaxial injector were investigated by the nonlinear $k-\epsilon-f_{\mu}$ model of Park et al.[1] and large eddy simulation (LES). In order to analyze the geometric effects on the scalar mixing for nonreacting variable-density flows, several recessed lengths and momentum flux ratios are selected at a constant Reynolds number. The nonlinear $k-\epsilon-f_{\mu}$ model proposed the meaningful characteristics for various momentum flux ratios and recess lengths. The LES results showed the changes of small-scale structures by the recess. When the inner jet was recessed, the development of turbulent kinetic energy became faster than that of non-recessed case. Also, the mixing characteristics were mainly influenced by the variation of shear rates, but the local mixing was changed by the adoption of recess.

$$
\text { 초 록 }
$$

동축제트분사기에 대한 난류유동의 특징이 비선형 $k-\epsilon-f_{\mu}$ 모형[1]과 큰에디모사법에 의해서 조사되 었다. 비연소조건에서 밀도가 다른 유체가 혼합될 때 레이놀즈수가 일정한 조건에서 리세스와 운동량 비가 변화되었다. 비선형 $k-\epsilon-f_{\mu}$ 모형은 리세스와 운동량비의 다양한 조건에서 의미있는 상관관계를 제안하였다. LES결과는 리세스에 의해서 난류유동 구조의 변화를 잘 묘사해 주었다. 리세스가 있는 경 우 난류운동에너지의 발달은 리세스가 없는 경우보다 빠르게 나타났다. 또한, 혼합특성은 전단변형률의 변화가 지배적이었지만 국부적인 혼합은 리세스에 의해서 변화되었다.
\end{abstract}

Key Words: Liquid Rocket Engine(액체로켓엔진), Coaxial Injector(동축분사기), Large Eddy Simulation(큰에디모사법), Recess(리세스), Scalar Mixing(스칼라혼합)

접수일 2011. 7. 18, 수정완료일 2012. 1. 12, 게재확정일 2012. 1. 19

* 종신회원, 경북대학교 기계공학부

1. 서 론

† 교신저자, E-mail: tsparkjp@knu.ac.kr 
동축분사기는 액체로켓엔진, 가스터빈 등의 연 소기에 핵심부품이고 화학반응로, 자동차엔진 노 즐, 각종 버너 등의 실제 시스템에 활용되고 있 다. 동축분사기에서 나타나는 연료와 산화제의 혼합특성은 유체역학적 주파수 특성을 변화시키 기 때문에 연소기 전체의 불안정성과 관계되어 설계에 매우 중요한 요소이다[2-5].

문헌조사에 의하면 동축분사기의 기본구조인 동축제트 유동에 대한 다양한 연구가 진행되어 왔다. 실험적인 연구들은 대부분 두종류 유체의 혼합은 와류유동 구조의 변화에 지배적이며 제 트들의 운동량비와 노즐lip 두께의 변화에 의해 서 혼합특성이 크게 의존함을 보여주고 있다. 이 를 바탕으로 Kiwata et al.[6]은 동축분사기와 유 사한 동축제트 유동에 대해 실험 및 해석적 연 구를 수행한 결과 비록 2차원 층류유동 조건이 지만 와유동의 공간적인 발달에 제트들의 형상 조건이 밀접하게 관계함을 증명하였다.

비연소 난류유동 조건에서 스칼라혼합은 유동 에 수동적인 형태로 특징이 나타난다. 그러므로 난류유동에 대한 정확한 해석이 선행되어야 한 다. 특히 연소기의 경우 분자수준에서 반응물들 이 혼합된 후에 화학반응이 발생되고 혼합특성 은 작은 에디(eddy)에 의해 지배된다. 또한 작은 에디들은 energy cascade에 의해서 큰 에디와 연관성을 가지고 큰 에디는 경계조건이나 물체 의 형상에 영향을 많이 받게 된다. 난류유동의 이러한 특징에 의해서 유동구조에 대한 분석은 일정크기 이상의 에디에 관한 변화를 명확하게 이해하여야 이루어질 수 있다. 최근에 Park과 Chung[7]은 동축분사기 형상에 대해 밀도변화가 있는 비연소 유동장에 대해 LES를 적용하여 여 러 형상조건에서 작은에디와 큰에디의 변화를 성공적으로 묘사하였다.

본 연구에서는 Park과 Chung[7]의 형상과 유 사한 조건에서 RANS 및 LES 해석을 수행하고 자 한다. 모사유체 조합과 형상변화에 대해서 Coherent Vortices의 구조 및 화학당량혼합거리 (Stoichiometric mixing length, $L_{S}$ )의 상관관계를 살펴보고자 한다.

\section{2. 수치해석 방법 및 검증해석}

\section{1 지배방정식}

밀도변화가 있는 비정상, 비압축성 난류유동에 대한 Park et al.[1]의 비선형 $k-\epsilon-f_{\mu}$ 모형 지배 방정식은 다음과 같다.

$$
\begin{gathered}
\frac{\partial \rho u_{i}}{\partial x_{i}}=0 \\
\frac{\partial \rho u_{i}}{\partial t}+\frac{\partial \rho u_{j} u_{i}}{\partial x_{j}}=-\frac{\partial p}{\partial x_{i}}+\frac{\partial}{\partial x_{j}}\left[\mu\left(\frac{\partial u_{i}}{\partial x_{j}}+\frac{\partial u_{j}}{\partial x_{i}}\right)-\tau_{i j}\right]
\end{gathered}
$$

레이놀즈 응력 $\tau_{i j}$ 는 다음식에 의해서 얻어진다.

$$
\begin{aligned}
& -\tau_{i j}=\nu_{t}\left(\frac{\partial U_{i}}{\partial x_{j}}+\frac{\partial U_{j}}{\partial x_{i}}\right)-\frac{2}{3} k \delta_{i j}-k \beta_{2}\left(S_{i k}^{*} S_{k j}^{*}-\frac{1}{3} S^{* 2} \delta_{i j}\right) \\
& -k \beta_{3}\left(W_{i k}^{*} S_{k j}^{*}-S_{i k}^{*} W_{k j}^{*}\right)-k \beta_{4}\left(S_{i l}^{*} S_{l m}^{*} W_{m j}^{*}-W_{i l}^{*} S_{l m}^{*} S_{m j}^{*}\right) \\
& -k \beta_{5}\left(W_{i l}^{*} W_{l m}^{*} S_{m j}^{*}+S_{i l}^{*} W_{l m}^{*} W_{m j}^{*}+0.5 S_{i j}^{*} W^{* 2}-\frac{2}{3} I I I_{S} \delta_{i j}\right)
\end{aligned}
$$

여기서 $I I I_{S}=S_{l m}^{*} W_{m n}^{*} W_{n l}^{*}, S_{i j}^{*}=S_{i j} k / \epsilon, \quad W_{i j}^{*}=W_{i j} k / \epsilon$, $S^{*}=\sqrt{2 S_{i j}^{*} S_{i j}^{*}}, W^{*}=\sqrt{2 W_{i j}^{*} W_{i j}^{*}}, \nu_{t}=C_{\mu} f_{\mu} k^{2} / \epsilon$ 등이 고, $S_{i j}, W_{i j}, \beta_{i}$ 는 전단변형률, 와도텐서, 전단변 형률의 함수인 계수를 각각 나타낸다. 감쇄함수 는 $f_{\mu}=f_{\mu 1} f_{\mu 2}$ 의 형태로 다음에 의해서 얻어진다.

$$
\begin{gathered}
f_{\mu 1}=\left(1+f_{D} R_{t}^{-3 / 4}\right) f_{w}^{2} \\
\frac{\partial^{2} f_{w}}{\partial x_{i} \partial x_{j}}=\frac{R_{t}^{3 / 2}}{A^{2} L^{2}}\left(f_{w}-1\right) \\
f_{\mu 2}=5.41 g /\left(g^{2}+A_{s}\right) \\
g=\left(\begin{array}{cc}
\frac{C_{0}}{3}+\left(P_{1}+\sqrt{P_{2}}\right)^{1 / 3} \\
+\operatorname{sign}\left(P_{1}-\sqrt{P_{2}}\right)\left|P_{1}-\sqrt{P_{2}}\right|^{1 / 3} & , P_{2} \geq 0 \\
\frac{C_{0}}{3}+2\left(P_{1}^{2}-P_{2}\right)^{1 / 6} \times & \\
\cos \left(\frac{1}{3} \arccos \left(\frac{P_{1}}{\sqrt{P_{1}^{2}-P_{2}}}\right)\right) \quad, P_{2}<0
\end{array}\right) \\
P_{1}=C_{0}\left[\frac{C_{0}^{2}}{27}-\frac{\left(A_{s}-\alpha_{2} \eta^{2}\right)}{6}+\frac{1}{2}\right] \\
P_{2}=P_{1}^{2}-\left[\frac{C_{0}^{2}}{9}-\frac{\left(A_{s}-\alpha_{2} \eta^{2}\right)}{3}\right]
\end{gathered}
$$


여기서 $A_{s}=\alpha_{3}^{2} \xi^{2}-\alpha_{2}^{2} \eta^{2} / 3, \quad \eta=f_{w} S^{*}, \quad \xi=f_{w} W^{*}$ 등을 나타낸다. 모델상수는 $C_{\mu}=0.09, A=8.4$, $\alpha_{1}=0.48, \alpha_{2}=0.375, \alpha_{3}=0.8, C_{0}=2.5$ 이다. 기 술되지 않은 난류운동에너지 방정식과 난류운동 에너지 소산율에 대한 방정식, 상수 및 계수 등 에 관련된 정확한 형태는 Park et al.[1]의 연구 에 자세히 검토되어 있다.

비선형 $k-\epsilon-f_{\mu}$ 모형의 지배방정식과 유사하 지만, LES에서 사용되어질 연속방정식, 운동량방 정식은 다음과 같다.

$$
\begin{gathered}
\frac{\partial \rho \bar{\rho} \bar{u}_{i}}{\partial x_{i}}=0 \\
\frac{\partial \rho \overline{u_{i}}}{\partial t}+\frac{\partial \bar{\rho} \overline{u_{j} u_{i}}}{\partial x_{j}}=-\frac{\partial \bar{p}}{\partial x_{i}}+\frac{\partial}{\partial x_{j}}\left[\mu\left(\frac{\partial \bar{u}_{i}}{\partial x_{j}}+\frac{\partial \overline{u_{j}}}{\partial x_{i}}\right)-Q_{i j}\right]
\end{gathered}
$$

여기서 $\bar{u}_{i}, \bar{p}, Q_{i j}=\overline{\rho u_{i} u_{j}}-\overline{\rho u_{i}} \overline{\rho u_{j}} / \bar{\rho}$ 는 필터가 적용된 속도, 압력, SGS응력을 나타내고, $\mu$ 는 점 성계수이다. SGS응력은 Lilly[8]의 동적모델을 이 용하여 $Q_{i j}=-2 \overline{C \rho} \bar{\Delta}^{2}|\bar{S}| \overline{S_{i j}}$ 와 다음의 관계로 얻어진다.

$$
\begin{gathered}
C \bar{\Delta}^{2}=-\frac{1}{2} \frac{<L_{i j} M_{i j}>}{<M_{k l} M_{k l}>} \\
L_{i j}=\overline{\bar{\rho}{\overline{u_{i}}}_{i}}-\overline{\overline{\rho u_{i}}} \overline{\overline{\rho u_{j}}} / \overline{\bar{\rho}} \\
M_{i j}=(\overline{\bar{\Delta}} / \bar{\Delta})^{2} \overline{\bar{\rho}} \overline{\bar{S} \mid \overline{S_{i j}}}-\bar{\rho} \mid \overline{\bar{S} \mid \overline{S_{i j}}}
\end{gathered}
$$

여기서, $\overline{S_{i j}}=0.5\left(\partial \overline{u_{i}} / \partial x_{j}+\partial \overline{u_{j}} / \partial x_{i}\right), \quad|\bar{S}|=\sqrt{2 \overline{S_{i j}} \overline{S_{i j}}}$ 이 고, $-\overline{.}, \overline{.},<.>$ 는 격자필터, 테스트필터, 평균 을 나타낸다.

밀도가 다른 유체의 비연소 혼합유동을 해석 하기 위하여 혼합분율방정식을 이용한다[7].

$$
\frac{\partial \bar{Z}}{\partial t}+\frac{\partial \bar{u}_{j} \bar{Z}}{\partial x_{j}}=\frac{\partial}{\partial x_{j}}\left[D\left(\frac{\partial \bar{Z}}{\partial x_{j}}\right)-s_{j}\right]
$$

여기서 $\bar{Z}, s_{j}=\overline{\rho u_{i} Z}-\overline{\rho u_{i}} \overline{\rho Z} / \bar{\rho}$ 는 필터가 적용된
혼합분율, SGS유속을 나타내고, $D$ 는 CHEMKIN-II[9]로 얻어지는 확산계수 이다. 비 선형 $k-\epsilon-f_{\mu}$ 모형의 경우 필터대신 시간평균이 적용된 방정식이고 $s_{j}=(\nu / 0.7) \partial \bar{Z} / \partial x_{j}$ 를 이용한 다. 비연소 상황에서 밀도와 점성계수의 변화는 다음과 같이 혼합분율의 함수로 결정한다.

$$
\begin{gathered}
\rho_{\text {mixture }}=\left(\frac{P_{o}}{T_{o}}\right) /\left[\bar{Z} R_{\text {fuel }}+(1-\bar{Z}) R_{\text {air }}\right] \\
\mu_{\text {mixture }}=\bar{Z} \mu_{\text {fuel }}+(1-\bar{Z}) \mu_{\text {air }}
\end{gathered}
$$

여기서, $P_{o} / T_{o}$ 는 상수이고 $\mathrm{R}$ 은 기체상수이다.

\section{2 이산화}

방정식들은 Green-Gauss 정리를 이용한 유한 체적법(Finite Volume Method)을 적용하여 이산 화하였다. 대류항 처리는 LES해석을 위해 4 차 정확도의 Compact차분법[10]을 적용하였다. 확 산항은 중심차분법을 이용하였고 압력과 속도장 의 연계성은 비정상 유동해석에 고정확도를 보 장하는 PISO 알고리듬[11-13]을 선택하였다. 이 알고리듬은 단계적인 압력수정 방정식을 사용함 으로써 비정상 해석에 요구되는 계산시간을 줄 일 수 있는 장점이 있다.

\section{3 검증해석}

본 해석에 앞서 코드의 예측성을 검토하기 위 하여 동축제트에 대한 해석을 수행하였다. 내부 제트유동이 $\mathrm{Air}, \mathrm{He}, \mathrm{CO}_{2}$ 일 때 실험[14]과 비교 하였다. 내부제트와 외부유동이 모두 공기일 때 는 밀도차이가 없지만 $\mathrm{He}, \mathrm{CO}_{2}$ 일 때는 밀도차 이로 많은 변화가 발생한다. 같은 속도비라도 밀 도변화에 의한 운동량이 변하기 때문에 혼합의 정도는 상이하게 나타난다. Fig. 1은 축방향 속 도의 순간적인 분포와 평균속도의 변화를 보여 주고 있다. 난류에너지 스펙트럼의 변화(-5/3 law)를 검토하여 약 80 만개에서 수행된 LES는 실험결과와 어느 정도 일치하는 결과를 보여주 고 있다. 그렇지만 비선형 $k-\epsilon-f_{\mu}$ 모형은 밀도 차이가 클수록 실험과 많은 차이를 보여주고 있 


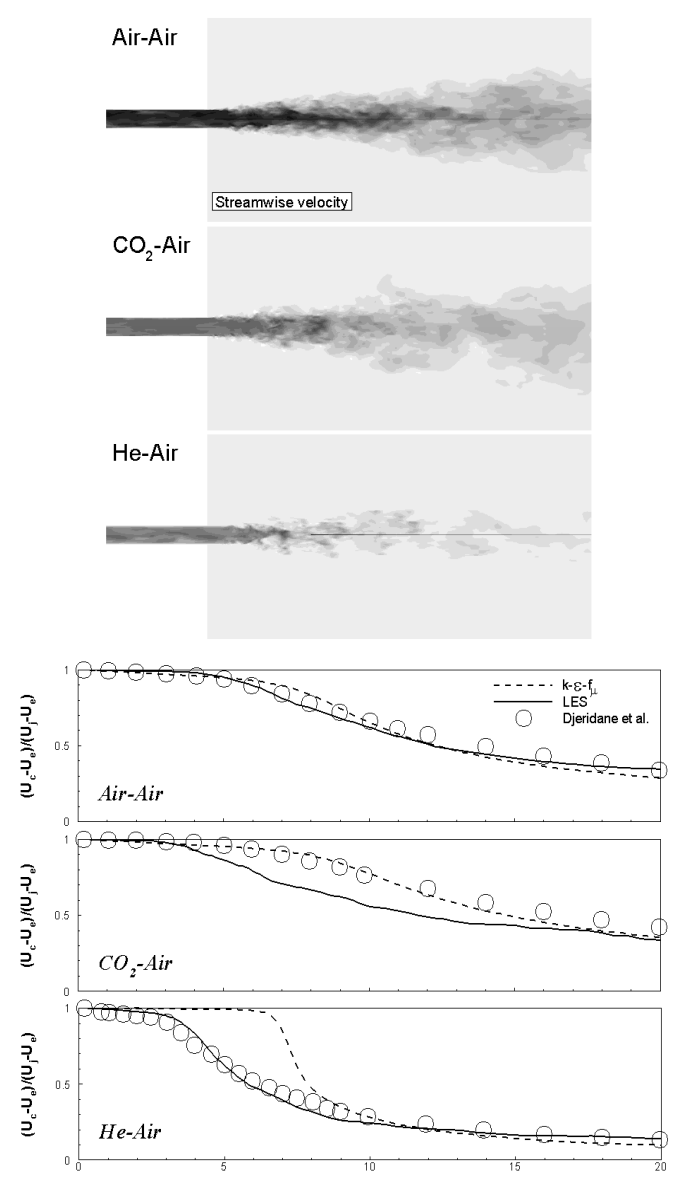

Fig. 1 Instantaneous and mean streamwise velocity along the jet axis of a round jet

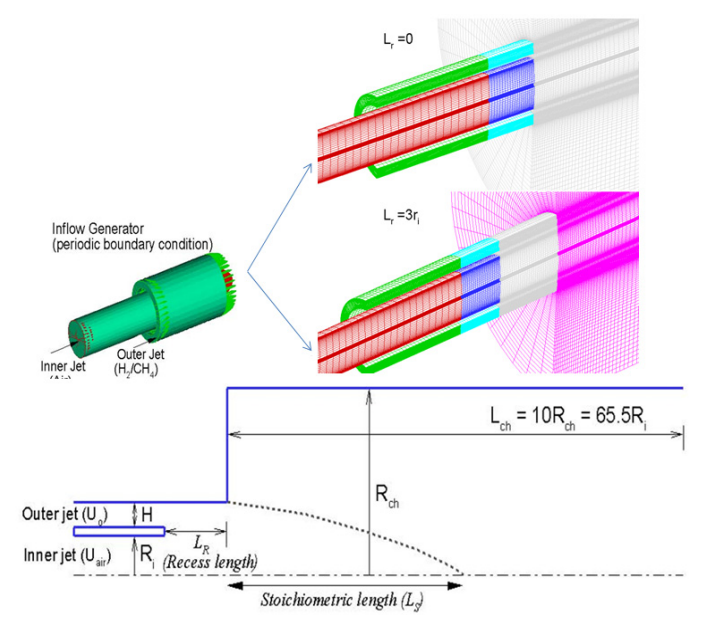

Fig. 2 Computational domain and grid system for a model injector
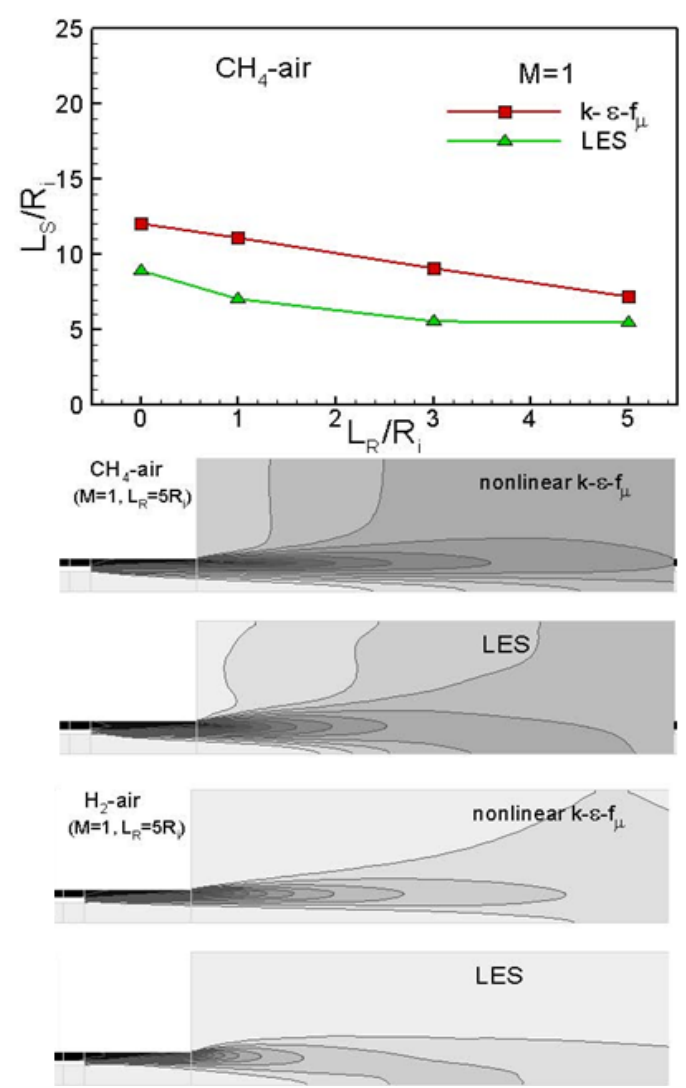

Fig. 3 Comparison of the predicted $L_{S}$ and timeaveraged Z

다. 이것은 밀도차이로 발생되는 난류운동에너지 의 변화에 대해 감쇄함수가 효율적이지 못한 것 에 기인한 것으로 생각된다. 또한 밀도변화가 존 재하는 경우 밀도변화가 없는 경우보다 격자수 가 많아야 좋은 결과를 줄 수 있을 것으로 기대 된다. 결과적으로 현재 계산과정은 신뢰성이 있 는 것으로 판단된다.

\section{3. 결과 및 고찰}

동축분사기에 대한 해석은 Fig. 2와 같은 형상 조건[7, 15]에서 격자수 100 만개 수준 (리세스가 없을 때 $962500 \mathrm{CVs}, L_{r}=5 r_{i}$ 일 때 1112500 $\mathrm{CVs}$ )을 이용하여 $R e_{o}=\rho_{o} U_{o} H / \mu_{o}=5000$ 일 때 RANS 및 LES해석이 수행되었다. 여기서 $\rho_{o}$ 는 
외부제트의 밀도, $U_{o}$ 는 외부제트 평균속도, $\mu_{o}$ 외 부제트 유체의 점성계수를 나타낸다. 내부 산화 제 제트유동 (반지름 $R_{i}$ )에 환형의 채널을 통해 연료가 공급되는 분사기 형상조건이다. $L_{r}=0$, $R_{i}, 3 R_{i}, 5 R_{i}$ 등의 리세스길이 변화에 운동량비 $M=\left(\rho_{o} / \rho_{i}\right)\left(U_{o} / U_{i}\right)^{2}$ 을 변화시켜가면서 해석이 수행되었다. $\rho_{i}$ 는 내부제트의 밀도, $U_{i}$ 는 내부제 트 평균속도이다. 형상조건 변화에 대해 전체적 인 경향성 파악은 비선형 $k-\epsilon-f_{\mu}$ 모형[1]을 이 용하였고 구체적인 유동구조의 변화를 살펴보기
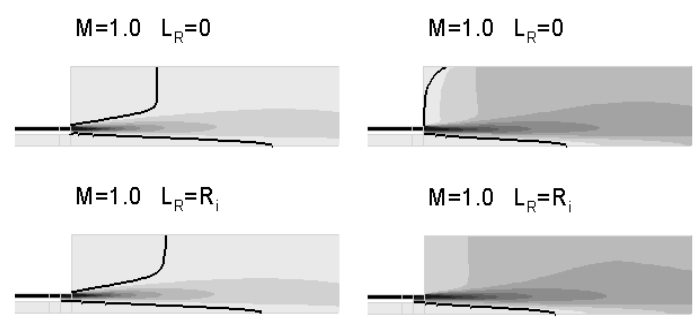

$M=1.0 \quad L_{R}=3 R_{i}$

$M=1.0 \quad L_{R}=3 R_{i}$

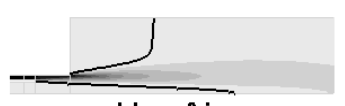

$\mathrm{H}_{2}-\mathrm{Air}$

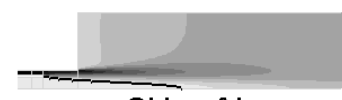

$\mathrm{CH}_{4}-$ Air

Fig. 4 Time mean mixture fraction
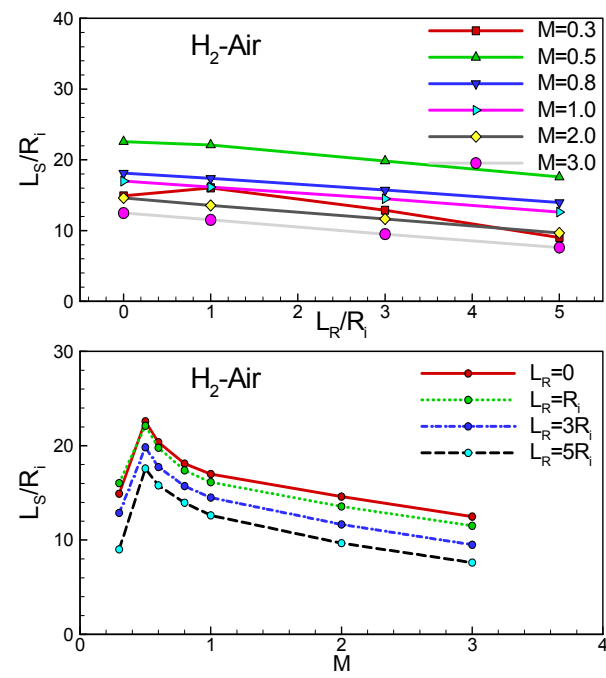

Fig. 5 Dependence of the stoichiometric mixing length on $M$ and $L_{R}\left(H_{2}-A i r\right.$, nonlinear $\left.k-\epsilon-f_{\mu}\right)$
위해 LES해석이 이용되었다.

Figure 3은 비선형 $k-\epsilon-f_{\mu}$ 모형 및 LES로 예 측된 화학당량혼합거리 $\left(L_{S}\right)$ 와 시간평균된 혼합분 율의 비교하였다. 여기서 $L_{S}$ 는 분사기 중심축상 에 화학당량 혼합분률 (Stoichimetric mixture fraction, $Z_{s t}$ )을 보여주는 분사면으로부터의 축 방향 거리를 나타낸다[16]. 연소생성물을 $H_{2} O$ 와 $\mathrm{CO}_{2}$ 로 가정하면 $\mathrm{H}_{2}-\mathrm{Air}$ 시스템의 경우 $Z_{s t}=\left[1+\nu Y_{\text {fuel, } 1} / Y_{O_{2} 2}\right]^{-1}=[1+8 / 0.233]^{-1}=0.0283$ 이 고, $\mathrm{CH}_{4}-\mathrm{Air}$ 일 경우 $Z_{s t}=0.055$ 이다. 결과에서 보면 비선형 $k-\epsilon-f_{\mu}$ 모형[1]의 경우 $L_{S}$ 는 리세 스길이 증가에 따라서 선형적으로 변하지만 LES 는 비선형적인 감소특성을 보여주고 있다. 시간 평균된 혼합분률의 분포를 보면 전체적인 분포 는 비슷하지만 축방향의 변화에서 많은 차이가 나타나고 있다. 이것은 작은에디의 변화가 적절 히 고려하지 못한 $k-\epsilon-f_{\mu}$ 모형의 특성으로 나 타난 차이로 생각된다.

Figure 4 는 리세스 변화에 따른 시간평균된 혼 합분율의 분포를 보여주고 있다. 여기서 실선은 화학당량 혼합분률값을 나타낸다. 내부제트의 후 퇴정도에 따른 혼합분율의 변화를 그림에서 살
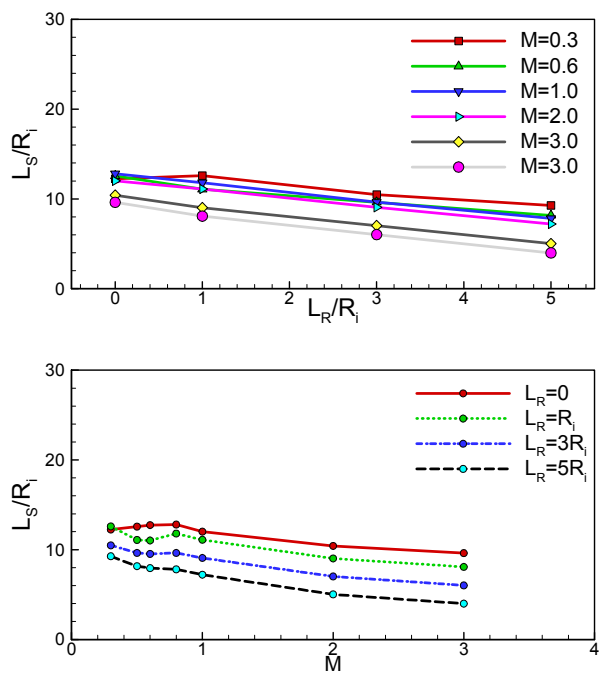

Fig. 6 Dependence of the stoichiometric mixing length on $M$ and $L_{R} \quad\left(C H_{4}-A i r\right.$, nonlinear $\left.k-\epsilon-f_{\mu}\right)$ 
펴볼 수 있다. 이러한 변화와 관련된 화학당량혼 합거리의 정량적인 변화를 살펴보기 위하여 Fig. 5 와 6 에 다양한 조건에 대한 화학당량혼합거리 의 변화를 나타내었다.

$H_{2}-\mathrm{Air}$ 인 경우 리세스의 증가에 따라서 혼합 거리는 거의 선형적으로 감소함을 보여주고 있 다. 화학당량 혼합거리가 감소는 평균유동관점에 서 리세스가 없는 경우와 비교할 때 리세스가 존재하는 경우 내부제트가 후퇴된 정도에 해당 된다. 그렇지만 Fig. 3에서 LES결과를 보였듯이 $L_{S}$ 는 리세스의 증가에 따라 비선형적인 감소를 보여준다. 즉 $L_{S}$ 의 변화는 내부제트의 후퇴길이 가 지배적이지만 작은 에디의 변화가 존재하기 때문에 비선형적인 변화를 나타내고 있는 것으 로 판단된다.

한편, 운동량비의 증가에 따라서 화학당량혼합 거리는 $\mathrm{M}=0.5$ 을 기준으로 다르게 나타나고 있 다. $\mathrm{M}=0.5$ 까지 혼합거리가 증가하고 있고 운동 량비가 $\mathrm{M}=0.5$ 보다 큰 경우 혼합거리가 감소하고 있다. $\mathrm{M}$ 이 1 보다 작은 경우 내부제트의 운동량 은 외부제트의 운동량보다 큰 조건으로 내부/외 부제트가 접한 위치에서 전단변형률변화 또한 상대적으로 커지게 된다. 결과적으로 내부전단층 에 발생된 유동의 변화가 스칼라 혼합을 $\mathrm{M}$ 이 1 보다 큰 경우보다 크게 유도하는 것으로 생각된 다. 혼합거리에 대한 이러한 증가-감소경향은 $\mathrm{CH}_{4}-\mathrm{Air}$ 인 경우 명확하게 나타나고 있지 않다. 이러한 차이는 공기에 대한 밀도차이가 다르기 때문에 얻어진 결과로 생각되지만 좀 더 자세한 연구가 필요한 부분이다. 그렇지만 운동량비가 $\mathrm{M}=1$ 인 조건을 중심으로 혼합거리의 변화가 다 르게 나타나고 있고 전체적으로 운동량비 증가 에 따라서 혼합거리가 감소하는 경향을 보여주 고 있다.

Figure 7 은 $H_{2}-A i r$ 인 경우 운동량비가 작을 때와 클 때 $\mathrm{z}$-방향 와도성분을 보여주고 있다. $\mathrm{M}$ 이 작을 경우 내부제트의 크기 증가로 positive 성분이 지배적으로 되기 때문에 내부의 공기제트는 반경방향으로 밀려가는 경향이 많아 지게 된다. $\mathrm{M}$ 이 클 경우 negative 성분이 지배
적으로 되어 외부 연료제트가 축중심으로 이동 이 강화되는 특징을 가지고 있다. 이러한 유동구 조에 의해서 Fig. 5에 나타낸 바와 같이 $\mathrm{M}$ 이 작 을 경우 혼합거리가 증가하고 $\mathrm{M}$ 이 클 경우는 혼합거리가 감소하는 특징을 가지고 있는 것으 로 생각된다.

Figure 8은 리세스 변화에 따른 특정위치에서 혼합분율의 확률밀도함수 (pdf)이다. 축중심상의 점에서는 $\mathrm{Z}$ 가 0 의 근처값에 분포하고 내부제트 반지름정도 반경방향으로 떨어진 위치해서는 $\mathrm{Z}$

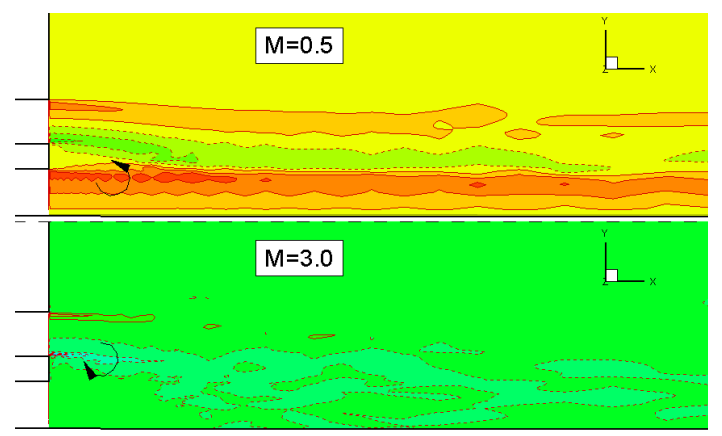

Fig. 7 Instantaneous $\omega_{z}\left(H_{2}-A i r\right.$, dasehed line: negative)

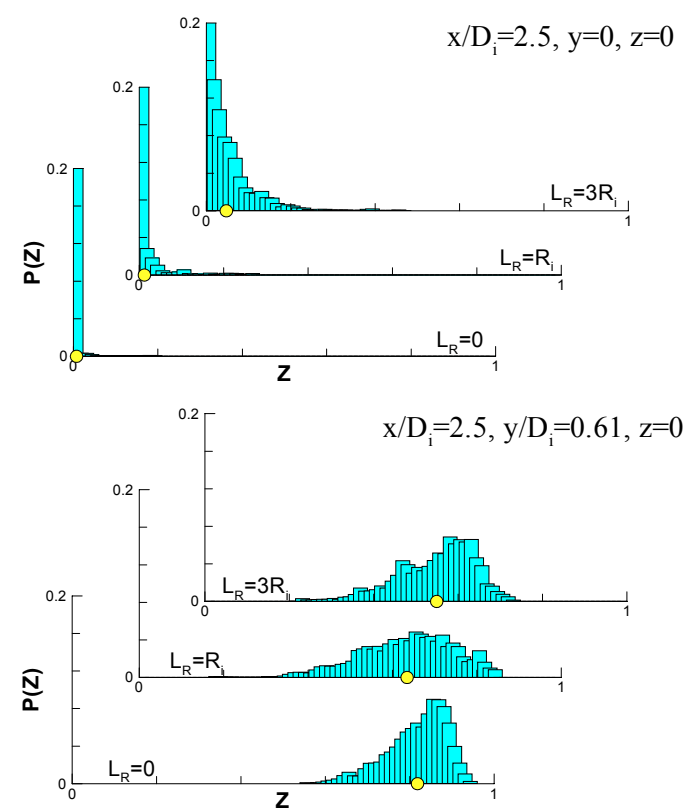

Fig. 8 Probability-density functions of the mixture fraction for $\mathrm{CH}_{4}-\mathrm{Air}$ jets 
(a) $\mathrm{CH}_{4}$-air

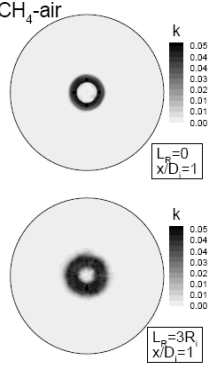

(b) $\mathrm{H}_{2}$-air

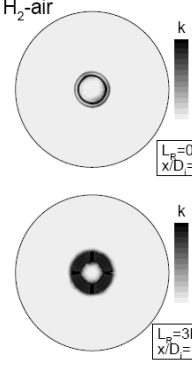

Fig. 9 Contours of turbulent kinetic energy at different positions $\left(D_{i}=2 R_{i}\right)$
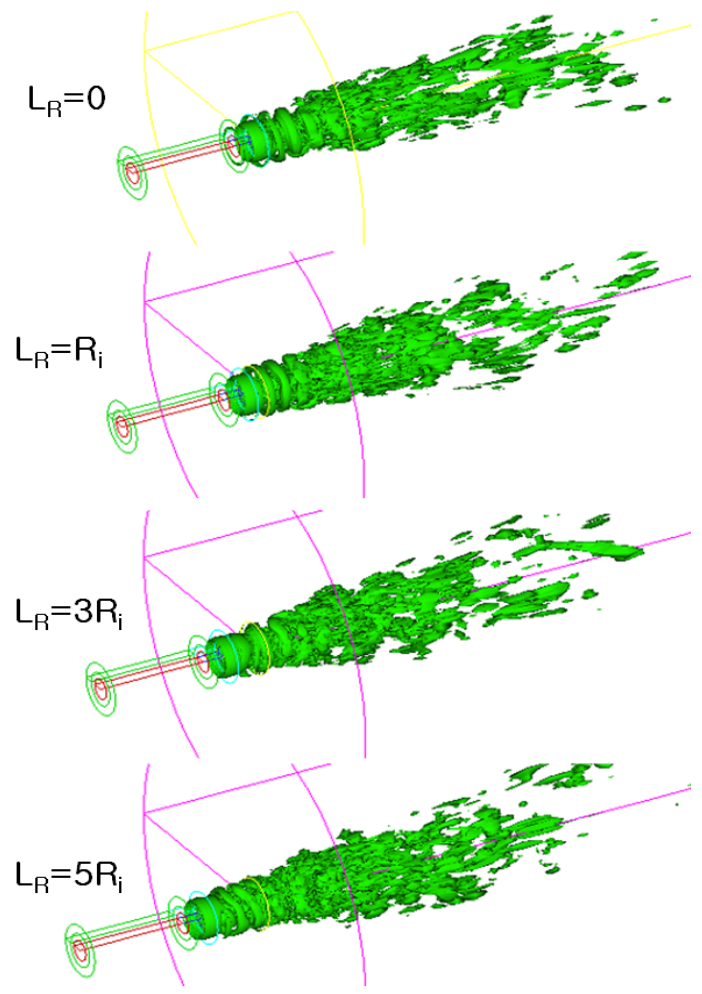

Fig. 10 Iso-surfaces of $\lambda_{2}$ by the vortex identification method $\left(\mathrm{CH}_{4}-\mathrm{Air}\right)$
가 0.5 보다 큰값에 분포하고 있다. pdf분포의 중 앙에 나타낸 점은 평균값을 의미한다. 리세스가 변하더라도 pdf의 특징이 크게 변하지 않기 때 문에 유동혼합구조는 한가지 형태임을 보여주고 있다.

Figure 9는 분사면으로부터 후류로 갈수록 발 달해가는 난류운동에너지 $\left(k=\overline{u_{i}^{2}} / 2\right)$ 의 변화를 보여주고 있다. 리세스가 없는 경우에 비해서 리 세스가 있는 경우 난류운동에너지의 반경방향으 로 발달이 빨리 이루지는 것을 보여주고 있다. 이러한 난류운동에너지의 변화는 유동장내에 존 재하는 와유동구조의 변화와 밀접한 관계가 있 다. 와유동구조를 나타내는 $S_{i k} S_{k j}+W_{i k} W_{k j}$ 텐서 의 2 번째로 큰 고유치로 정의되는 $\lambda_{2}$ [17]를 이용 하여 변화를 살펴보았다. 여기서 $W_{i k}$ 는 와도텐 서이다. Fig. 10은 $\mathrm{CH}_{4}-\mathrm{Air}$ 인 경우 리세스 변 화에 따른 난류에너지 생성과 관계된 와유동
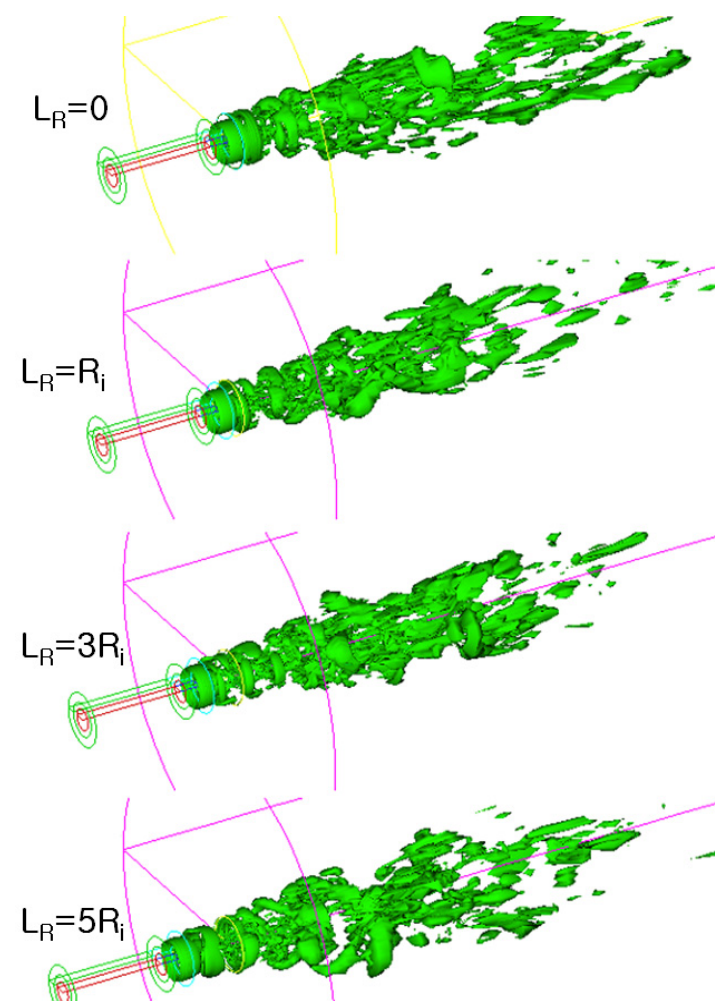

Fig. 11 Iso-surfaces of $\lambda_{2}$ by the vortex identification method $\left(H_{2}-\right.$ Air $)$ 
(streamwise vortices)구조를 보여주고 있다. 전 단층의 불안정성(Taylor-Helmholtz)과 관계된 링 형태의 와유동 구조가 리세스에 의해서 변하고 있고 후류에 작은 크기의 와유동구조가 많아지 는 형태를 보여주고 있다. 밀도차이 큰 경우 Fig. 11에서 보는 바와 같이 와유동구조는 큰 스 케일의 구조가 지배적이고 리세스에 의해서 발 달하는 형태가 변하고 있다.

Park과 Chung[7]은 리세스가 있는 동축분사기 에서 리세스가 존재할 경우 내부/외부제트 사이 에서 발생된 큰구조의 와유동이 전단층 불안정 성에 의해서 작은구조로 빨리 변해가는 특징이 있음을 보여주었다. 이러한 유동구조는 화학당량 혼합거리의 변화와 밀접한 관련이 있을 것으로 생각되어 Fig. 12에 리세스 변화에 따른 화학당 량 혼합거리의 자기상관계수를 살펴보았다. 그림 에서 보면 작은 주기의 성분들이 리세스가 증가 할수록 많아지는 특징을 보여주고 있다. 이것은 리세스의 도입이 유동장에 주기가 작은 유동구 조를 야기한다고 생각할 수 있다. 이러한 특징은 연소영역의 비정상거동에 영향을 줄 수 있을 것 이지만 Fig. 9-11과 함께 생각해보면 리세스의 도입은 난류확산을 증가시켜 연소불안정보다는 연소효율증가에 기여할 것으로 생각된다.

\section{4. 결 론}

본 연구에서는 전단변형률을 이용하는 동축분 사기 모형에 대하여 수력학적인 특징을 파악하 기 위하여 운동량비와 리세스의 길이 변화에 대 한 난류유동해석을 수행하였다.

비선형 $k-\epsilon-f_{\mu}$ 모형[1]과 LES로 예측된 결과 를 비교한 결과 밀도차이가 있는 유동에 대한 모 델수정이 필요하였지만 공학적인 유용성이 확인 되었다. 비선형 $k-\epsilon-f_{\mu}$ 모형[1]의 경우 리세스길 이 증가에 따라서 화학당량 혼합거리는 거의 선 형적으로 변하지만 LES는 비선형적인 감소특성을 보여주었다. 운동량비의 변화는 화학당량 혼합거 리의 비선형적인 변화를 보여주었다. 특히 밀도차 이가 큰 $\mathrm{H}_{2}-\mathrm{Air}$ 와 밀도차이가 작은 $\mathrm{CH}_{4}-\mathrm{Air}$

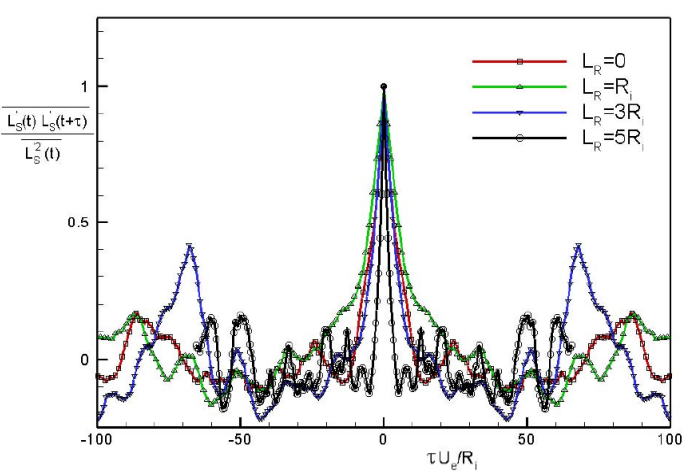

Fig. 12 Autocorrelation coefficients of $L_{S}$ on $L_{R}$ $\left(H_{2}-\right.$ Air,$\left.M=1\right)$

의 경우 화학당량 혼합거리는 매우 다르게 나타 났다. 이러한 변화는 내부/외부 제트유동의 전단 층 불안정성과 관계된 것으로 나타났다.

리세스가 존재하는 경우 리세스가 없는 경우 와 비교할 때 내부제트가 후퇴된 정도의 화학당 량 혼합거리가 감소함을 보여주었다. LES결과는 이러한 선형적인 변화에 난류섭동 성분의 변화 로 화학당량 혼합거리가 비선형적으로 변함을 보여주었다. 이러한 비선형성은 화학당량 혼합거 리의 자기상관계수 변화를 살펴본 결과 작은 주 기의 성분들이 리세스 증가에 따라 많아지는 특 징으로부터 확인할 수 있었다. 동축분사기에서 리세스효과는 평균유동보다 난류에너지를 증가 하는데 효과가 있음을 의미하는 것으로 생각된 다. 결과적으로 리세스의 도입은 연소영역의 비 정상거동에 영향을 줄 수 있을 것이지만 난류확 산을 증가시켜 연소불안정보다는 연소효율증가 에 기여할 것으로 예측되었다. 그렇지만 연소해 석을 통하여 추가적인 연구가 이루어져야 동축 분사기에서 리세스 도입의 정확한 효과를 판단 할 수 있을 것이다.

$$
\text { 후 기 }
$$

본 연구는 한국연구재단을 통해 교육과학기술 부의 우주기초원천기술개발 사업(NSL, National Space $\mathrm{Lab}$ )으로부터 지원받아 수행되었습니다 (No.20090091793). 


\section{참 고 문 헌}

1. Park, T. S., Sung, H. J. and Suzuki, K., "Development of a nonlinear near-wall turbulence model for turbulent flow and heat transfer," Int. J. Heat and Fluid Flow, Vol. 24, 2003, pp.29-40

2. Sasaki, M., Sakamoto, H., Takahashi, M., Tomita, T. and Tamura, H., "Comparative Study of Recessed and Non-Recessed Swirl Coaxial Injectors," AIAA 1997-2907, 1997

3. Bazarov, V. G. and Yang, V., "Liquid-Propellant Rocket Engine Injector Dynamics," Journal of Propulsion and Power, Vol. 14, 1998, pp.797-806

4. Kendrick, D., Herding, G., Scouflaire, P., Rolon, C. and Candel, S., "Effects of a Recess on Cryogenic Flame Stabilization," Combution and Flame, Vol. 118, 1999, pp.327-339

5. Bazarov, V. G., Yang, V. and Puneesh, P., "Design and Dynamics of Jet and Swirl Injectors," In Yang, V., Habiballah, M., Hulka, J. and Popp, M. (Eds.) Liquid Rocket Thrust Chambers: Aspect of Modeling, Analysis and Design, Progress in Astronautics and Aeronautics, 2004, Vol. 200, pp.19-104

6. Kiwata, T., Okajima, A., Ueno, Hisanori and Kimura, S., "Vortex Frequencies of Coaxial Jets", International Conference on Fluid Engineering, Tokyo, Japan, 1997, pp.111-116

7. Park, T. S. and Chung, Y. M., "Turbulent Flow and Scalar Mixing of a Coaxial Injector Having Two Fluid Jets," Numerical Heat Transfer Part A, Vol. 60, 2011, pp.197-211

8. Lilly, D. K, "A Proposed Modication of the Germano Subgrid-Scale Closure Model," Physics of Fluids, Vol. 4, 1992, pp.633-635

9. Kee, R. J., Rupley, F. M. and Miller, J. A., "CHEMKIN-II: A Fortran Chemical Kinetics
Package for the Analysis of Gas-Phase Chemical Kinetics," Technical Report SAND89-8009, Sandia National Lab, 1990

10. Lele, S. K., "Compact Finite Difference Schemes with Spectral-Like Resolution," J. Coumputational Physics, Vol. 103, 2000, pp.16-42

11. Issa, R. I., "Solution of the Implicitly Discretised Fluid Flow Equations by Operator-Splitting," Journal of Computational Physics, Vol. 62, 1986, pp.40-65

12. Park, T. S., "Effect of Time-Integration Method in a Large Eddy Simulation Using PISO Algorithm: Part I - Flow Field," Numerical Heat Transfer Part A, Vol. 50, 2006, pp.229-245

13. Park, T. S., "Effect of Time-Integration Method in a Large Eddy Simulation Using PISO Algorithm: Part II - Thermal Field," Numerical Heat Transfer Part A, Vol. 50, 2006, pp.247-262

14. Djeridane, T., Amielh, M., Anselmet, F. and Fulachier, L., "Velocity turbulence properties in the near-field region of axisymmetric variable density jets," Physics of Fluids, Vol. 8(6), 1996, pp.1614-1630

15. Foust, M. J., Desphande, M., Pal, S., Ni, T., Merkle, C. L. and Santoro, R. J., "Experimental and Analytical Characterization of a Shear Coaxial Combusting $\mathrm{GO}_{2} / \mathrm{GH}_{2}$ Flowfield jets," AIAA 34th Aerospace Science Meeting \& Exhibit, AIAA 1996-0646, Reno, 1996

16. Schumaker, S.A. and Driscoll, J.F., "Coaxial Turbulent Jet Flames: Scaling Relations for Measured Stoichiometric Mixing Lengths", Proceedings of the Combustion Institute, Vol. 32, 2009, pp.1655-1662

17. Jeong, J. and Hussain, F., "On the Identification of a Vortex", J. Fluid Mech., Vol. 285, 1995, pp.69-94 